\title{
Promoting Environmental Education for Primary School-aged Students Using Digital Technologies
}

\author{
John Buchanan ${ }^{1}$, Kimberley Pressick-Kilborn ${ }^{1 *}$, Damian Maher ${ }^{1}$ \\ ${ }^{1}$ University of Technology Sydney, New South Wales, AUSTRALIA
}

Received 29 March 2018 - Revised 13 August 2018 - Accepted 26 October 2018

\begin{abstract}
As demands on the environment continue to intensify, it becomes increasingly urgent to act sustainably, responsibly and respectfully, to protect and restore environments. Digital technologies, including videoconferencing, mobile apps and virtual and augmented realities, can provide new ways of engaging students in environmental stewardship. Such technologies can pique student interest, while enabling them to capture experiences of local and distal environments, to collect data and share their findings with broader audiences. This article critically explores innovative, formal and informal learning practices in experiential environmental education approaches among schools, families and communities, such as citizen science projects. It draws on qualitative case study vignettes, as well as the authors' previous work and broader literature, to consider the potential and limitations of such technologies and approaches. The key question concerns how existing and emerging technologies might serve as bridges or barriers to apprenticing young people into globally-minded, environmentally responsible and respectful behaviours.
\end{abstract}

Keywords: authentic pedagogies, citizen science, digital technologies, primary school environmental sustainability education, learner engagement and interest

\section{INTRODUCTION}

The natural environment grows increasingly fragile. Processes such as global warming and rising sea levels already impact all life including human life (Wigley, 2018), and problems such as plastic waste (Wilcox, Van Sebille, \& Hardesty, 2015) and habitat destruction (Turner, Oppenheimer, \& Wilcove, 2009) are global in scale. Such changes and problems demand increased collective and individual efforts to maintain and restore ecosystems. Young people in particular have much invested in the future of the environment and their actions today will leverage significant future dividends, for better or for worse.

The pedagogical approaches underpinning environmental education initiatives in school and community settings can be highly effective in capturing young people's interests, and promoting the importance of environmental stewardship and action (Bellino \& Adams, 2017). We argue that student-centred, inquiry-based approaches, such as project-based learning, are important in providing opportunities for students to engage with local and global real-world problems, sometimes in connection with experts in the field. Through these approaches, both schools and broader communities can achieve important pro-environmental outcomes.

In helping to conserve, protect and manage the environment, digital technologies have an important contribution to make. Two particular roles highlighted in this article are enhanced student engagement in sustainability initiatives, and data sharing towards improved environmental and biodiversity activism. It is our view that technological innovations are of limited use in promoting environmental education except under clear pedagogical guidelines. We have adopted 'digital technologies' as a cover-all term; "digital technologies includes computer-based learning and multimedia materials and the use of networks and communications systems to support learning. Learning Technologies clearly embraces a wide range of applications" (Rist \& Hewer, 1996, p. 2).

(C) 2019 by the authors; licensee Modestum Ltd., UK. This article is an open access article distributed under the terms and conditions of the Creative Commons Attribution License (http://creativecommons.org/licenses/by/4.0/). \John.Buchanan@uts.edu.au $\boldsymbol{\square}$ kimberley.pressick-kilborn@uts.edu.au (*Correspondence) 


\section{Contribution of this paper to the literature}

- Contexts highlighted span out-of-school and in-school learning with discussion of possibilities and limitations of digital technologies in presenting (dis)connections in primary school-aged students' engagement in environmental education initiatives.

- Illustrative vignettes and related analyses provide insights into current and envisaged uses of new and emerging digital technologies in sustainability education, including local and global data sharing.

- Focus on primary school-aged students' participation in technology-enhanced citizen science projects as contexts for promoting environmental stewardship.

An overarching question guiding our research is, 'How might digital technologies (dis)connect young people to or from their environments?'

The research objectives comprise:

1. Exploring environmental practices in primary aged learning;

2. Examining how the use of technology can support such practices.

In examining the overarching question and in meeting the objectives, we first examine the literature. We then present five vignettes, or scenarios, drawn from our previous research and professional work. The vignettes illustrate ways that environments are being - and in future, could be - used by children and young people, with support from the adults in their lives. Each vignette focuses on environmental education and digital technology use for children of primary school age, in or beyond school. The five vignettes are presented and analysed in turn. Discussion of themes arising from the vignettes then follows, focused on the pedagogical approaches that can support sustainability learning outcomes (Gündüz, Aşıksoy, \& Öksüz, 2018), and how digital technologies can complement such approaches. The article concludes with discussion of a number of implications, framed by consideration of the associated prospects and pitfalls of using digital technologies in environmental education.

\section{REVIEW OF LITERATURE}

As asserted at the outset of this article, the imperative for adopting sustainable lifestyles is ever-increasing (Buchanan, Schuck, \& Aubusson, 2016). Cheng, Lou, Kuo, and Shih (2013, p. 96) describe environmental change as "serious, urgent and increasing". Cebrián and Junyent (2015) concluded that environmental education needs to be a holistic affair (encompassing policy, practice, management and pedagogy. One aim of environmental education is "to change a child's relationship with nature" (Cheng et al., 2013, p. 96), that is, to help the child-adult develop and maintain "a profound attachment to place" (Zapf, 2010). In short, a primary school's responsibility is to apprentice children into informed environmental stewardship and wherever possible, this responsibility should be shared with each child's family.

The environment is not only a rich source for sustaining life, but also a rich source for sustaining what Kuh (2008, p. 13) identified as, "high impact learning", including approaches such as experiential learning (Kolb, 1984), inquiry learning, and problem- and project-based learning (Aditomo, Goodyear, Bliuc, \& Ellis, 2013; Krajcik \& Czerniak, 2014). Sustainability education also invites learners (and teachers) to be part of something bigger than themselves.

Real and virtual environments can be seen as a continuum rather than a dichotomy (Huang, Chen, \& Chou, 2016). And yet, each approach or mode, formal, in-school, or "not-school learning" (Greenhow \& Lewin, 2016, p. 10 ) is typified by certain features. The following section will explore the importance of environmental education and the affordances of digital learning tools, and will then examine some of the problems and limitations that may need to be countenanced.

\section{Environmental Education and Digital Learning Tools}

Environmental education should operate within and upon learners' cognitive, affective or attitudinal, and conative, that is, action-oriented dimensions (Weng, Hu, Tao, \& Xu, 2018). Cebrián and Junyent (2015) call for "transformative social learning" in this regard. Effective related pedagogies should be transformative in all three of Weng et al.'s (2018) dimensions, above: cognitive, affective and conative. According to Cebrián and Junyent (2015), the teaching of environmental sustainability requires "knowledge, practical skills, tools, attitudes and ethical values". 'Tools' include digital technologies. To be useful, such tools should serve to enhance one or more of Cebrián and Junyent's (2015) other four requisites above for environmental education - knowledge, skills, attitudes or values.

All education, including sustainability education, depends heavily on, and should be measured against, its outcomes, such as those enumerated above. A variety of approaches can be used to enhance its outcomes. 
Renninger and Hidi (2016), and Olmos-Raya et al. (2018), set forth the importance of interest and engagement in learning. To be effective and engaging, sustainability education should be explicitly purposeful (Janis, Birney, \& Newton, 2016), intentional and goal-oriented. The title of the project that Janis et al. (2016) investigated, the Billion Oyster Project, announces its goal in its title. Similar sustainability projects might include habitat restoration, as part of disrupting human disruption of the natural environment, or litter reduction campaigns. Measurable goals could be expressed in terms of the area of habitat restored or cleared of litter, sightings of key species over time and the like.

Triggering, sustaining and developing interest is a sine qua non of effective education (Pressick-Kilborn, 2015). $\mathrm{Tu}$, Chen and Chen (2017) note the influential power of digital technologies on young people, which underscores the importance of related education, including consumer, critical and ethical literacies. Ardoin, Giano, Bundy, Chang, Holthuis and O'Connor (2014) examined fieldwork in terms of generation of interest, and found field studies promising in terms of better understanding the extent and nature of student interest. They conceded, however, that longitudinal studies would be necessary to determine the duration of such effects. Nurturing interest and awareness through environmental education, is a necessary but insufficient condition for the ultimate goal of such education. Sustainability education proves its worth by precipitating lifelong behaviours that demonstrate an increased sense of responsibility to, and respect for, the environment; such behaviours will extend the life and quality of the aggregate of habitats, including human habitat, that constitute the environment.

Gaming, including digital gaming, has been shown to add a stratum of purpose to a sustainability education goal, albeit potentially an arbitrary one, potentially unrelated to environmental outcomes. Students might or might not be 'learning naturally' in such circumstances. Accordingly, maximising a game's verisimilitude can be part of the game-master's quest. Cheng et al. (2013) interviewed 32 students who had undertaken a new approach using digital game-based learning, deriving from the board game Monopoly. They found that respondents considered the approach highly motivating, particularly compared to the unspecified previous approaches they had undertaken.

While, as stated above, engagement is an insufficient measure of commitment to the environment, it nonetheless provides a pathway for students to easily absorb more knowledge about environmental care (Hiller \& Katsantas, 2014). Lu and Liu (2013) developed, implemented and evaluated a marine education approach with lower primary aged students. They devised a hybrid approach, integrating virtual and physical learning approaches, including augmented reality and gaming. Lu and Liu (2013) discerned that the approach met two key metrics: student engagement, and acquisition of target knowledge. Moreover, the approach helped lower-achieving students in particular. Similarly, Flagg (2016) found the strongest learning outcomes for minority students who engaged with digital learning tools. Liu, Gong, and Chen (2018) identified positive learning and sustainability outcomes from a related virtual reality teaching approach. Chen and Chou (2016) tested and elicited evaluative responses from three groups of students, using either only virtual devices, only a human teacher, or a combination of both. They obtained the best results from the group experiencing a combination of human and virtual input. This suggests the value of designing blended approaches in pedagogy.

Among the benefits of digital learning technologies, Greenhow and Lewin (2016, p. 7) include "new forms of inquiry, communication, collaboration, identity work" and "positive cognitive, social, and emotional impacts". Perhaps the greatest affordances of digital tools is their capacity for the low-cost, low-impact and immediate transfer of information, which provides several valuable learning affordances, as outlined below:

- connection to distant or potentially dangerous, unhealthy, disturbing or restricted environments, by 'virtually delivering' students to such environments (or vice-versa). Such environments might include the seabed, clifftops, caves, an apiary, a volcano, an orbiting space shuttle or a demilitarised zone. Seasonal variations and inclement weather can also restrict field trips. Virtual encounters appear to reduce fears associated with an environment (Hummel \& Randler, 2010). Problems of distance might apply most particularly to urban environments, which are otherwise information-rich, but typically lacking in access to natural surroundings. As more and more children grow up in cities, and in apartments, as opposed to houses with yards, so will they become increasingly dislocated from natural environment (Janis, Birney, \& Newton, 2016). Nevertheless, as Janis, Birney, and Newton's Billion Oyster Project, based in New York, indicates, there remain opportunities for urban children - arguably the most pressing opportunities. Such connection may also serve as an equaliser for learners with limited mobility or funds, or in remote locations. The safety aspect may be especially propitious for very young children. Digital technologies also present the best-todate means of virtually transporting students through time, to explore environments under previous conditions, or under extrapolated future conditions.

- connection to (big) data, as well as the opportunity to contribute to it. Implicit in such access is students' and teachers' critical literacy and rigour, in terms of accessing reliable sources, and contributing the highestquality, most accurate and relevant data possible. 
- connection to supplementary 'augmented' information and experiences, through the layering of additional information over environmental representations whether local or distant, and associated collection and interpretation of data, with existing products such as Green Maps (Lai, Chang, Li, Fan \& Wu, 2013), or products devised by teachers (Schönfelder \& Bogner, 2017). As indicated above, this layering might also be time-related.

- connection to experts, such as scientists, astronauts or national park rangers (Huseal \& Abd-El-Khalick, 2014; Le Féon et al., 2016), to other learners, and to each other outside of school hours.

- connection to a wider potential audience, for the purposes of educating or recruiting them, and for garnering feedback.

- connection to like-minded and like-hearted learner-citizens elsewhere, providing opportunities for collaboration and cross-pollination of ideas, and circumventing teacher-centred, didactic approaches (Greenhow \& Lewin, 2017). Vogel, Kurti, Milrad, Johansson and Müller (2014, pp. 43-44) refer to "mobile science inquiry collaboratories" in this regard. Ardoin et al. (2014) found peer interaction to be a significant trigger of interest. Moreover, beyond-school peer interaction further blurs the distinction between formal and informal learning. Associated opportunities might relate to: knowledge of and care for watercourses and catchment areas, perhaps along an entire watercourse ('Live Stream'?), or an extended length of coastline, which might also monitor sea level rises ('Sea Change'?) through inter-school collaboration along a coastline or catchment. Such an approach might realise a sense of shared responsibility, cause and effect (especially along a river catchment), and power through numbers, as well as the capacity for and benefits of team-building. The quality of peer input is an important consideration here, however; preparing habitat for, and monitoring the annual arrival of, migratory birds; creating plant-based habitat-corridors for local birds, or otherwise 'greening' local neighbourhoods; The GreenWay Sustainability Project (Inner West Council and City of Canterbury-Bankstown, 2017) is one example of such an initiative, involving several local schools, in Sydney's inner western suburbs; recycling endeavours and the like. Regarding seasonal bird migration, the metaphor of tidying and otherwise preparing the home for guests might be useful for younger learners.

Digital platforms also provide a context for motivational student-driven problem- or project-based learning approaches. In particular, such technologies undergird and facilitate citizen science projects (Krazny \& Tidball, 2009; Propen, 2015) with their propensity for learner participation and agency (Bandura, 1989), and real-world benefits (Cooper, 2016). Indeed, agency may well be a crucial factor in addressing the complex, large-scale problems of environmental degradation. Citizen science projects can achieve a number of purposes. They might identify and tally or otherwise measure:

- threatened or vulnerable species (Flagg, 2016),

- invasive species (Delaney, Sperling, Adams \& Leung, 2008),

- less 'endearing', non-iconic species (Zeegers, Paige, Lloyd, \& Roetman, 2012),

- diseases, debris, toxins or other threats (Lewis, Oliver \& Oliver, 2017; van der Velde et al., 2017), or

- changes over time (Albers, Lange \& Xu, 2017).

As intimated above, such approaches might operate at local or broader environmental scales, perhaps across several or multiple schools, as well as other organisations, such as government, business or the media.

Moreover, and importantly, virtual learning encounters tread more lightly on the environment, preserving it for future (virtual) visits. This applies not only to the site itself, but also in terms of associated travel. Virtual encounters also reduce impact on animal habitat and behaviour. While this is a crucial part of the equation, we also concede that a virtual experience cannot substitute for real encounters with real environments, habitats or species. In the following section, we enumerate and discuss some of the problems and limitations of using digital learning tools for sustainability education.

\section{Problems, Limitations and Prospects}

Greenhow and Lewin (2016) observed that educational use of web 2.0 technologies is under-theorised. Vogel et al. (2014), among other researchers, have reported the limitations of existing software and hardware vis-à-vis the educational demands placed on them.

Information currently provided by sustainability learning sites, such as botanic gardens, is inadequate, according to Huang, Chen, and Chou (2016), who added that, "disorganized and unsystematic visits to such facilities result in low learning effectiveness" (p. 74). Virtual learning can find itself prone to similar shortcomings, as evidenced by terms such as 'browsing', and metaphorically 'surfing'. And yet, such approaches, and what they unearth, might constitute powerful and permanent learning experiences, as noted by Ardoin et al. (2014). 
Negotiating who controls what is to be learnt (students, teacher or curriculum) may be a central issue in this regard. Curriculum potentially presents a limitation for sustainability education and/or digital approaches, and it may be that the curricular and assessment trees must bend to the breeze of student interest here. As in any educational endeavour, but perhaps particularly with sustainability, a sense of student agency and hope of effecting a positive impact is crucial (Ballard, Dixon, \& Harris, 2017). Greenhow and Lewin (2016, p. 12) speak of "participatory digital cultures" in this regard.

Virtual encounters with the environment are arguably an inferior substitute for real-time and real-place encounters. Nevertheless, circumstances may make virtual encounters the only viable option. Schönfelder and Bogner (2017) observed that, "direct experiences with nature are regarded as crucial, but using an eLearning tool in environmental education constitutes an outstanding alternative to acquire knowledge" (p.723). They conceded, though, that environmental attitudes (as opposed to knowledge) are better supported through direct interface with nature.

While gaming appears to be a highly engaging pedagogical approach, it may have limitations with regard to real-world authenticity. The metaphor or allegory in a chosen game may fail to entirely match the circumstances of reality. Similarly, a game may well fail to capture the complexity of a system. This might also be regarded as a virtue, however, in its capacity to present simplified, digestible realities to younger learners, all the while maintaining the game's capacity to teach environmental responses and responsibilities. Nevertheless, we recommend that games might be used principally as a means to introduce students to greater complexities, and perhaps as foreplay for real environmental encounters. Games can be devised and gradated accordingly, to 'take learner-gamers to the next level' which can also maintain motivation. Other limitations include the technological expertise of teachers, issues of privacy and vulnerability of data, and cost, capacity and storage of data. Linked to the matter of expertise, limited teacher confidence with digital technologies may serve to constrict their adoption in classrooms (Liu, Ritzhaupt, Dawson, et al., 2017). While we do not wish to extol such limitations on the part of teachers, they may open the way to more student-led undertakings.

In short, despite their limitations, digital approaches are to be lauded for their emancipatory capacity - the potential to liberate from, liberate for, and liberate through. We now proceed to discuss some recent and potential examples of digital technologies for environmental sustainability ends. First, we detail the process of vignettewriting. We then present the vignettes in turn with analytical discussion pertinent to the individual vignette. The broader discussion that follows the vignettes draws out key themes and important pedagogical features from across all five vignettes, with reference to the literature reviewed.

\title{
SELECTION AND DEVELOPMENT OF VIGNETTES
}

\begin{abstract}
"Rarely are vignettes used as a means to simulate complete reality. Rather vignettes are used to simulate partly elements of the topics under study. Vignettes are selective" (Hughes \& Huby, 2004, p. 46).
\end{abstract}

The vignettes presented here were collaboratively identified and developed, initially through discussion amongst the article's three authors. We drew on data collected in research that we individually had undertaken, as well as our personal engagement and professional work in environmental, science and technology education in community, school and tertiary settings. In the process of identifying and developing the small collection of vignettes, we were guided by two key criteria: (1) the capacity of the collection to enable a broad range of associated pedagogical approaches, and (2) the scope within the collection to encompass a range of digital technologies, both current and emerging. We have treated each vignette as a case (Yin, 2014), for the purposes of analysis, comparison and evaluation of their virtues and limitations.

The first step in the process was individual writing of a short case narrative, which was then examined by the other authors and refined to draw out and emphasise features considered significant for discussion in light of the literature reviewed. Each narrative and analysis was then collaboratively developed as a further step. We then took a step back to compare features of the vignettes for the purposes of discussion. Our findings concerning the vignettes emerged in part through a grounded theory analytical approach (Strauss \& Corbin, 1997).

Although not all of the vignettes are examples of citizen science initiatives, analysis of each one was informed by a framework for deliberate design of citizen science projects proposed by Bonney, et al. (2009) and elaborated by Shirk, et al. (2012) through the addition of Typologies 1 and 5, below. The framework can be considered as a continuum, and the typologies are described as follows by Shirk, et al. (2012) based on degrees of participation:

Typology 1: Contractual projects, where communities ask professional researchers to conduct a specific scientific investigation and report on the results.

Typology 2: Contributory projects, which are generally designed by scientists and for which members of the public primarily contribute data. 
Typology 3: Collaborative projects, which are generally designed by scientists and for which members of the public contribute data but also help to refine project design, analyse data, and/or disseminate findings.

Typology 4: Co-Created projects, which are designed by scientists and members of the public working together and for which at least some of the public participants are actively involved in most or all aspects of the research process.

Typology 5: Collegial contributions projects, where non-credentialed individuals conduct research independently with varying degrees of expected recognition by institutionalised science and/or professionals.

We have classified Vignettes 1 and 2 as contributory projects, while we consider Vignette 4 as a collegial contributions project and Vignette 5 a collaborative project. Vignette 3 is more difficult to neatly classify, being an education program featuring different aspects of contributory, collaborative and co-created projects.

Cooper $(2016,2018)$ emphasises that there are different design features of associated typologies, in relation to the language used, and types of activities supported. Contributory projects, for example, tend to focus on creating a 'community of interest', while co-created projects build a 'community of place' (Cooper, 2016, 2018). Regardless of where a project or initiative sits on the continuum, Cooper $(2016,2018)$ emphasises the potential of citizen science participation in opening people to other ways of knowing. She makes a particular call to teachers: "When teachers can offer authentic, hands-on science experiences, students can gain a love for discovery and a lifelong curiosity to understand not only what is already known but also what is not yet known" (Cooper, 2016, p. 278).

Our cluster of vignettes that follows does not presume to capture the entirety of approaches or digital technologies being used in environmental education. These illustrative scenarios, however, may prompt discussion, application and adaptation of other examples of projects using digital technologies to support environmental education for young people. Three of the vignettes are based on current practice, while two envisage practice that is likely to be realised in the near future. Vignettes one and two are paired for similarity, with each examining existing family-linked practices involving primary school-aged children, but with implications for teachers in primary school contexts. The third vignette focuses on the importance of teacher professional learning about digital technology integration in environmental education. In this vignette, consideration is given to how primary preservice teachers can be supported to better understand how technologies can be used to promote students' environmental education. Vignettes four and five explore possible future digital technological developments and implications for primary school-based teaching and learning. All individuals' names are pseudonyms.

\section{Vignette 1: Gamification of Environmental Education - The QuestaGame Experience}

Kate and her nine-year-old son Marley share a love of native wildlife and always have enjoyed watching nature documentaries together and spotting lizards, spiders and frogs in their inner city, urban garden. When Kate and Marley were watching Behind the News (Australian Broadcasting Corporation, 2018) one evening, there was a segment about a new app, QuestaGame (https://questagame.com/btn-video/). They decided that it would be an interesting way of sharing their wildlife spotting with others, as well as finding out more about what species are being observed nearby. After downloading the app to their mobile devices, they started capturing their finds by taking and uploading photographs to the Questagame app as they walked through the local streets and around the nearby harbourside parkland. They noticed that they each had more birds in their collections than other types of animals, so they then started hunting for different types of spiders, butterflies and skinks. The more information they shared by adding field notes to their sightings and making correct identifications, the more 'gold' they collected, providing them with status and rewards within the game. In time, Marley joined a clan within QuestaGame, and was excited when it won 'Clan of the Day', helped by his sightings. Kate and Marley decided to create a quest for other players and were keen to see whether other QuestaGame players would join it. They discussed how difficult they should make the Quest, and added a commonly sighted bird in their neighbourhood as well as a couple of rarer ones to increase challenge for other gamers.

\section{Analysis of the QuestaGame vignette}

Kate's and Marley's active participation in a local bioquest through the QuestaGame app is motivated by both collaborative and competitive features of the game. In-built collaborative features include the clan membership and the possibility of creating quests for other QuestaGamers. The way in which Kate and Marley use the app together, however, also promotes their shared interest in exploring, and raising awareness of, the biodiversity in their local environment. In-built competitive features of the QuestaGame design include the reward structure, with feedback given on sightings and 'gold' awarded for correct identification and useful field notes contributed to sightings. 'Gold' can be used to purchase virtual supplies such as bottles of water and 'photography tech'. Without photography tech, gamers are prevented from taking pictures of their wildlife sightings. While this particular vignette illustrates out-of-school involvement in QuestaGame, teacher resources and a dashboard are features that can be adapted for primary school-based environmental education. Teachers could plan a class or school challenge, including the possibility of students setting quests for one another or joining and contributing to a school-based 
clan. Primary students could be encouraged to play Questagame during breaks in the school day, during particular lesson times, or on weekends and after school.

Such an app provides an 'equaliser' for young players, as there are no age limits, and sightings are judged by experts on the quality of the image uploaded, the rareness rating of the sighting for the location, and detail added by the gamer in field notes. Data from QuestaGame are contributed to the Atlas of Living Australia (https:/ / www.ala.org.au/), an open access database, which also links to a searchable database of Australian citizen science projects supported by the ALA. Finally, while Kate and Marley are drawn to the app because of an existing interest in their local environment, there is the potential for QuestaGame to raise environmental awareness and engage a new group in an environmental initiative; gamers stereotypically can be found on their couches indoors, rather than out exploring nature. In primary schools, there may be such interest amongst gamers so as to support the formation of a QuestaGame co-curricular club.

\section{Vignette 2: Bioacoustic Monitoring and the FrogID App}

Sally works in a large financial services firm and in early 2018, she attended a corporate function at the Australian Museum in Sydney. Sally was not a regular visitor to the Museum or an active citizen scientist; in fact, she would not really identify herself as 'science-y'. She became inspired, however, when she heard the Museum's charismatic Curator of Amphibian and Reptile Conservation, herpetologist Dr Jodi Rowley, explain her field research and the recent discovery of a new species of frog. Dr Rowley then shared the successful recent launch of a national frog identification project. The project is being led by the Australian Museum, facilitated through a free app, FrogID, as the data gathering tool, and supported by a website that is designed as an engagement platform (https:/ / www.frogid.net.au/). The FrogID app enables citizen scientists to use the microphone on a smartphone to record a frog's distinctive call, which is then uploaded alongside location data. Calls are then identified by experts and added to a bioacoustic database, incorporating other information about each species.

Before Sally left the Museum function, she had already downloaded the app and over the next weekend, she and her three primary school-aged children went 'frogging' for the first time. The first frog call they recorded was identified by FrogID experts as a Striped Marsh Frog, which the family discovered is a fairly common species in the Sydney region. They had not realised that frogs were such important environmental indicators or found in such diverse habitats, and were surprised by how many other people were interested in frogs and were adding their recordings to FrogID. As a family, they spent some time exploring and reading the frog profiles on the FrogID website, talking with each other and comparing frog habitats and calls. They wondered - and sometimes laughed - together at the range of intriguing sounds that different frogs make! Next, Sally and her children are planning to create a frog-friendly section of their own garden which is located near some tracts of remnant bushland and a large national park in Northern Sydney. They have read the 'How to make a frog pond' slides in the 'Classroom resources' section on the FrogID website, and they've decided to make this a family project in the approaching school holidays.

\section{Analysis of the FrogID vignette}

The FrogID initiative is an example of a project that could not be undertaken - or would be difficult to undertake, given the scope, scale and associated costs - through traditional science and so requires citizen science. Sally and her children provide an example of first time citizen scientists, who have been attracted to a national, high profile initiative in the case of FrogID through Sally's experience of triggered interest upon hearing a passionate, knowledgeable frog expert speak. The recording function of smartphones means that owners have a pocket-sized device for acoustic monitoring, making this technology available as a tool individually. Sally found it easy and accessible for her family to participate and contribute local data. The vignette also exemplifies this family's sense of agency in adapting their own garden to attract frogs. Taking local action is important in many environmental education initiatives. Along with her children, Sally appeared to realise that people power can make a difference; but also important to acknowledge is the lift in morale that comes from knowing there are other enthusiasts. Again, this vignette reflects one family's participation in a citizen science project, focusing on the context of community environmental education and its role in raising awareness of conservation, biodiversity and the importance of habitat preservation. The FrogID website is not solely community focused; there is information for primary and secondary schools, including how teachers can sign up their class to participate and provision of classroom resources to support students' action-learning about frog classification, frog habitats, adaptations and food webs. 

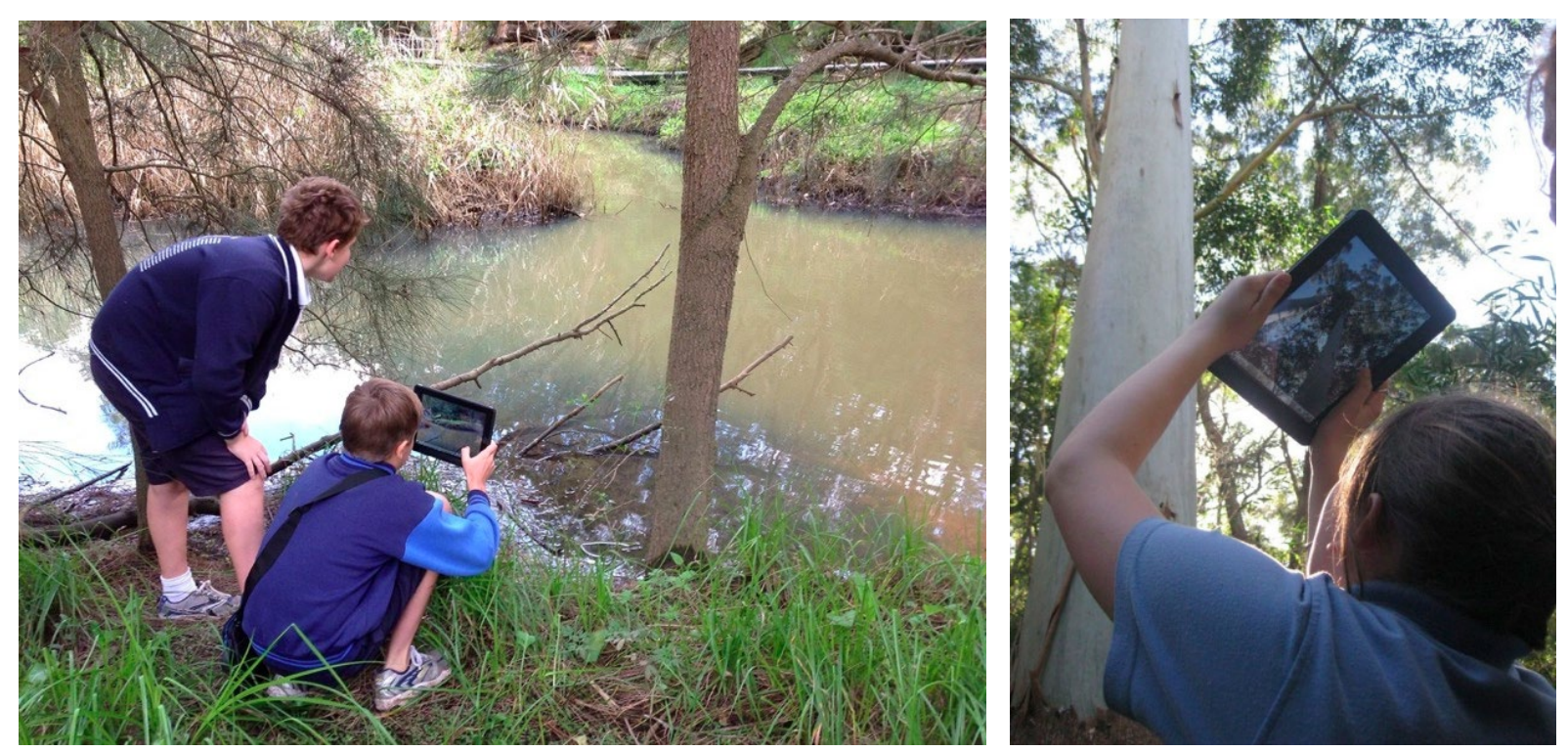

Figure 1. Students use iPads to photograph and share their field observations. (Images sourced from http://fieldofmarseec.nsw.edu.au/student-learning/gallery/ 15 March 2018; used here with permission.)

\section{Vignette 3: Preservice Teachers Learning how to Integrate Digital Technologies to Promote Primary Students' Environmental Education}

In a field-based Professional Experience as part of their teacher education course, primary preservice teachers are placed in a range of out-of-school learning settings, including Environmental Education Centres (EECs)

(http://www.environment.nsw.gov.au/sustainableschools/manage/EnviroCentres.htm). The preservice teachers undertake their placement in groups of three to four, and undertake planning, implementation and evaluation of activities with primary school students, with the leadership and guidance of an experienced environmental educator on site. One particular EEC is Sydney's Field of Mars (http://fieldofmarseec.nsw.edu.au/), which has developed a number of digital learning resources to support students' learning before, during and following a school field trip. This EEC has sought to model and lead environmental education that integrates digital technologies. These technologies include video conferences ('Connected Classrooms Lessons') on topics such as spiders, life cycles, and trees as habitats, as well as interactive, multimodal 'Multi-touch Books' that are free to download and supportive of primary students' learning related to the Australian Curriculum (ACARA, n.d.). The EEC was one of the first in Australia to use iPads to support primary students' environmental education experiences in bushland settings (Figure 1). When preservice teachers undertake their placement at the Field of Mars EEC, they observe use of these technologies, and have occasion to utilise such technologies in their own practice teaching at the site.

\section{Analysis of the Preservice Teachers vignette}

One of the recognised challenges in initial teacher education is to provide firsthand, state-of-the-art professional experiences to inspire and provoke preservice teachers' thinking about pedagogical possibilities in their future work in schools (Burn \& Mutton, 2015; Darling-Hammond, 2017). The opportunity to participate in the field-based delivery of an environmental education program that actively integrates digital technologies offers such a provocation. During their short-term placement with staff at the Field of Mars EEC, the preservice teachers engage with students and in-service teachers. This face-to-face engagement supports preservice teachers' insights into environmental teaching and learning through tailored and purposeful technologies, to enhance primary students' understandings of sustainability. Preservice teachers then present a reflective report to their peers and lecturers upon return to campus, so that they are exposed to a range of sites and pedagogies for promoting school-based learning beyond the classroom. With this knowledge, they are better equipped to champion and lead innovative sustainability education with future primary students.

\section{Suggestions for future study and practice: Vignettes 4 and 5}

The final two vignettes feature emerging technologies and how we envisage these being incorporated to promote primary students' environmental education in the foreseeable future. 


\section{Vignette 4: Augmented Reality - Students Supporting Community Involvement at the Local Park}

This vignette extends from work undertaken for a research project with a group of four Sydney primary schools where a project-based learning approach was adopted to support associated learning. The students were presented with an overarching question: 'How can we create a product that benefits a group within our local community?' From this broad question, students were encouraged to devise their own driving question. One such question was, 'How can we support non-English speaking community members to use and enjoy our suburb?' One school focused on exploring a riverside walk and designing a digital product that informed users of the walk. One of the groups of students used a paid trial app maker produced an app that users could download via a QR code provided at either end of the walk. They then proposed to install the QR codes at strategic points along the walk.

In developing this project further and envisaging what may be possible in the future, the app would connect to a number of augmented reality features. The first of these would superimpose previous environments over the current one. The students would undertake associated research using old photos. This feature would serve the local park well, as it was an old army site in inner Western Sydney. Additionally, the feature would allow users to 'visit' pre-colonial times to explore traditional Indigenous land uses, including food production and manufacture of tools. This app would connect to websites which the students would produce, and link to Youtube video clips made by themselves or others.

A second AR feature involves scanning some of the flora and fauna with their app, which would superimpose, for example, the flowers of plants currently not in bloom. Animal sounds also could be included. Additionally, the app could 'capture' and identify existing plants and animals, and provide related information. More detailed information could be obtained via the app's links to websites.

A third feature that could support young people's engagement with the area would be a treasure hunt which would be undertaken via the augmented reality feature. The users would seek particular objects or animals, which would support and assess students' environmental learning using game-based learning principles. The purpose of such learning would be to understand how to best remediate the site if needed. The app would allow participants to connect to each other's devices so that they share information with each other, such as scat sightings.

\section{Envisaging potential uses of AR}

In using the technology, students are engaged in a real-world experience supported by a project-based learning approach. In using the approach, the teacher assumes a greater facilitative role, with less direct instruction and increased 'just-in-time', teacher contribution. Whilst project-based learning has numerous benefits there are also pitfalls. One such pitfall is resourcing. Given that students tend to focus on slightly different aspects of a topic or issue, a wide variety of resources is needed, which can be difficult for schools to resource. Given this complexity, it can be problematic for teachers to provide appropriate modelling and timely feedback, to facilitate individual and cooperative learning and to engage students in meaningful assessment and self-reflection to guide the project-based learning process (Barron \& Darling-Hammond, 2008).

In Vignette 4, the app supports learning and engagement across the community including the students, other park users and the local council. The historical features including natural and built environments can be superimposed over the existing setting. Users can experience flora and fauna in the natural setting that may be absent at that time; for example, a nocturnal animal or one that is seasonally present. The app provides data analytics to the teacher to support assessment of student learning. Students also can analyse data user engagement. Parents can be connected to their child's learning via the app both in real time, and via a summary of the experience. The app connects students to each other so they can share ideas and information. The students and teacher have access to other users, including students at other schools, which enables comparative analysis. At this stage, the ease of use for app development is not accessible to most students of primary school-age, or to primary school teachers. It thus seems likely that some time will pass before this type of technology becomes mainstream and widespread.

\section{Vignette 5: Virtual Reality and Native Lizards - Imagining New Technological Affordances}

This scenario is not yet fully possible but as virtual reality (VR) technology advances, it is approaching actuality. A primary school is located near a nature reserve. The local National Parks and Wildlife (NPAW) Department wants to develop a new walking track. The NPAW staff enlists student help to design a VR app that allows the students to construct different options and then assess the impact on a local endangered native lizard population. The VR system that they are using allows multiple users to interact simultaneously in the same virtual reality 
environment (currently, most systems only allow one user to interact in a VR environment at one time). The headsets are self-contained and connect to the base station via bluetooth, providing freedom of movement for users.

The students collaborate with NPAW staff to devise three scenarios with minimal impact on the lizards, and trial the three scenarios themselves and collect associated data. The NPAW staff provides specialist knowledge in developing the scenarios. Based on their findings, students tentatively recommend the track that least impacts the lizards and their habitat. They then invite interested park users to the school to interact with the three scenarios via the VR system. Once the students have collected sufficient data, they report to NPAW staff on the track deemed least destructive, and elaborate and share their findings.

The NPAW staff then constructs the path based on their own and the students' data, contributing their own expert knowledge where needed. The students are invited, virtually and through on-site visits, to help monitor the use of the new path and the impact it is having on the local lizard population through the continued collection and analysis of data in conjunction with NPAW staff. Data could be collected and live-streamed in real time by a remotely controlled miniature button camera.

\section{Envisaging potential uses of VR}

The technology featured in this final vignette provides opportunities for industry, government and schools to collaborate. Participating primary students undertake scientific observation as well as data collection and analysis with meaningful, real-world outcomes. They are supported to develop a repertoire of associated communication and organisation skills.

Engaging young people as citizen scientists supports their involvement in environmental projects and enables them to contribute their own locally gathered data to a larger dataset. The collection of data requires careful management, however. To ensure reliability and validity of student-collected data, both teachers and students need training in appropriate data gathering and interpretation. Such training can reduce bias - "the tendency to overreport some occurrences and under-report others - which may affect the study's expected outcomes" (Shah \& Martinez, 2016, p. 20). Having the appropriate technologies and knowledge of their use can also improve data validity and reliability. Uniformity, reproducibility and efficacious use of collected data are further important considerations (Garbarino \& Mason, 2016).

\section{Discussion of the Vignettes: Digital Technologies as Bridges or Barriers?}

The five vignettes provide illustrative case narratives of how digital technologies are, and could be, integrated into environmental education for primary school-aged students. Across the vignettes, two key pedagogical themes arise that offer bridges to engagement in environmental education: authenticity and personalisation. Digital technology integration, however, can also keep learners at a distance from the environments they seek to study.

We use the term 'authenticity' here to signify that the environmental problems and tasks are real rather than contrived by a textbook or a teacher. All five vignettes involve real-world activities or tasks, with real audiences such as the community, families, peers and experts. Additionally, the projects all seek real-world solutions enhanced environmental understanding and stewardship. Real-world learning resonates with approaches such as inquiry learning and project-based learning (Maher \& Yoo, 2017; Wang, Lavonen, \& Tirri, 2018). These approaches are learner-centred (Moursund, 1998) providing students and the broader community with opportunities to participate collaboratively in real-life situations where they co-construct learning with personal significance and relevance (Smith, diSessa, \& Roschelle, 1993). Primary school-aged students are positioned through such approaches as solvers of real-world environmental problems through experiential projects and actions undertaken (Aditomo et al., 2013; Kolb, 1984).

Another common pedagogical theme across the vignettes is personalisation of students' learning. In using this term, we mean the tailoring of the learning, allowing for student direction, with an emphasis on student agency and inquiry, for example through bioquests and games. McNight et al. (2016) identified personalisation as an important contribution from digitally-mediated teaching and learning approaches. As noted above, digital technologies can support student inquiry through pedagogical approaches such as project-based learning. These devices enable communication amongst students at any number of schools, and with experts in the field and community members. Video conferencing and live camera technologies also allow students to experience realworld places to which they normally would not have access because of remoteness, or danger to themselves or to the particular environment and its inhabitants. One such example is Birdlife Australia's 'Eagle Cam', which provides a live camera feed of a white-bellied sea eagle nest in western Sydney, beside the Parramatta River (http://www.birdlife.org.au/visit-us/discovery-centre/eagle-cam). These raptors are the second largest bird of prey in Australia. Their nests are built high in trees, sometimes up to 30 metres above the ground, rendering them otherwise inaccessible. 
Integrating environmental education and digital technologies is not risk-free, however, and may erect barriers, not bridges, to engagement. One potential risk we see with exclusive use of digital learning tools to encounter the environment is that young people might end up doing - or learning - 'virtually nothing'. An associated recommendation we make is that virtual experiences, where practicable, could be used as a forerunner to and appetiser for, rather than an alternative to, environmental interface. "Experiencing nature with all of one's senses is the heart and soul of science...Experiencing nature with all of one's senses is also the heart and soul of being human" (Cooper, 2016, p. 27). We are not advocating digital technology integration as a replacement for the environmental experience, or for access to the 'real thing' wherever practicable and possible. Sensory immersion and emotional connection are key to environmental learning, as our vignettes exemplify. Emotional connection may be experienced through a sense of awe or wonder. It can also be precipitated through engagement with likeminded and like-hearted others in collaborative sustainability initiatives, and we recognise the capacities of digital approaches in this regard. In a number of our illustrative vignettes, opportunities for contact, involvement with, or feedback from experts in their field, whether face-to-face or facilitated by digital technologies, provide children and adults with more substantial site-specific knowledge than would otherwise be practicable. Such opportunities also can open up possibilities for students to identify - and to be identified - as 'apprentice' environmental and citizen scientists.

\section{IMPLICATIONS AND CONCLUSIONS: PROSPECTS AND PITFALLS?}

In this article, we have discussed the already-established capacity for digital technologies to connect learners in various ways. Similarly, learner engagement, or connection-to-the-activity, is a widely-acclaimed virtue of digital technologies. We trust that engagement and connection to the task will be evident in mobile learning activities, but we recognise that this will not always automatically be so for all learners. Moreover, as asserted above, we see engagement as a necessary but insufficient condition for learning to occur. We now review some features of the cases we investigated. We do not wish to adjudicate each case, but we draw inferences from them, and the qualities that they embody, to a greater or lesser degree. We propose the following as a possible framework or checklist for teachers and others engaging with digital technologies for environmental purposes. We use the term 'engagement' here as a cover-all for phenomena such as interest and participation. Specifically, we discuss engagement, and reprise the theme of connection, with regard to scientific method, real-world issues, learning, and action.

- Connection to rigorous, scientific method (not 'just sitting at the kiddies' table'?)

Shirk et al.'s (2012) framework presented above, from contractual to co-created projects, illustrates this dimension. One quest for digital technologies, as for all science education, is to apprentice learners into rigorous, sceptical, evidence-based scientific inquiry and thought - to be scientists. Such critical approaches have application for many areas of life, such as the social sciences, interpretation of texts and the like. Such an approach will also enable young learners to make real contributions to data collection, analysis and outcomes. It will allow them to be co-creators and colleagues of scientists, to the extent that this is possible. Vignette 5, the lizards, perhaps best exemplifies this, as well as real-world connections, below.

- Connection to the real-world, or relevance (real-world learning?)

Digital technologies such as games and apps present environmental metaphors or similes, both of which are well-tested rhetorical devices for learning (Buchanan, 2015; Aubusson, Harrison, \& Ritchie, 2006), explaining the unknown in reference to something known. Nevertheless, metaphors and similes present imperfect comparisons. Moreover, simplification through metaphor or simile can be a virtue or a vice. One test of a digital learning approach is its proximity to environmental realities, that is, its authenticity (Nordby, Knain \& Jonsdottir, 2017). This is an important foundation for the two dimensions that follow, learning and action. There may be occasions where parallaxes are tolerable in context of other virtues of the approach, but teachers and learners need to become adept at identifying and explaining such shortcomings.

- Connection to learning (the play's the thing?)

We ask ourselves here, what might this (device, approach etc.) look like in the hands of a good teacher (Rowe, 2014). It is vital for teachers to transcend the seduction of the game, to drive, craft and shape digital learning approaches, and to demand educationally worthy features and outcomes thereof. Such approaches need to (with apologies to Shakespeare's Hamlet) 'catch the conscience of the kids', and lead them to a place of greater environmental respect and responsibility. If not, such devices are mere playthings. Vignette 4 illustrates this well, as children discuss and debate uses of actual and virtual worlds. The Environmental Education Centre apprentices pre-service teachers well into such an approach.

- Connection to action (agents for change or just 'secret agents'?)

Here we add 'responsiveness' to respect and responsibility, above. We advocate connection to activity, not just to the activity at hand (Buchanan, Schuck, \& Aubusson, 2016). We want learners to look through and beyond their 
screens, not just at them, in order to be agents of change. As with learning, above, role-playing detectives or the like is noble, while ever it apprentices users into greater powers of observation and deduction; or into becoming agents provocateurs. We ask here how mobile devices can mobilise learners into action and advocacy. Games and the like have been shown to effect positive reinforcement - but the ultimate positive reinforcement is environmental (re)habilitation. For example, vignettes 1 and 2 capture more than bird images and frog sounds respectively; an important by-catch is users' determination to protect species and habitats.

Respect, responsibility and responsiveness - what we are referring to as the Rs of sustainability education demand whole-person responses from learners that are affective, cognitive and conative or action-based, in nature. We recognise the double meaning of 'in nature' here. Digital technologies and devices afford a range of valuable opportunities to interact virtually with nature or with representations thereof, with minimal impact on the environment. But such approaches need to operate in the service of pro-environmental and pro-pedagogical ends. We encourage teachers to embrace these new technologies; engagement and familiarisation with such technologies will allow effective environmental teaching and appropriate use of technologies and tools to orchestrate. Underpinning this, however, teachers need to remain mindful of the learning and sustainability outcomes that such tools can obstruct or effect.

\section{ACKNOWLEDGEMENTS}

Thanks to the University of Technology Sydney's STEM Education Futures Research Centre for a grant to support this publication. Thanks also to Ruth Fentie for her research assistance. We also thank the participants in the research projects drawn upon in vignettes 1,2 and 3.

\section{REFERENCES}

ACARA (n.d.). Australian Curriculum. Retrieved on $15 \quad$ March 2018 from https://www.australiancurriculum.edu.au/

Aditomo, A., Goodyear, P., Bliuc, A., \& Ellis, R.A. (2013). Inquiry-based learning in higher education: Principal forms, educational objectives, and disciplinary variations. Studies in Higher Education, 38(9), 1239-1258. https:/ / doi.org/10.1080/03075079.2011.616584

Albers, B., Lange, N., \& Xu, S. (2017). Augmented citizen science for environmental monitoring and education. The International Archives of the Photogrammetry, Remote Sensing and Spatial Information Sciences, XLII-2.

Ardoin, N., Giano, M., Bundy, J., Chang, S., Holthuis, N., \& O'Connor, K. (2014). Using digital photography and journaling in evaluation of field-based environmental education programs. Studies in Educational Evaluation, 41, 68-76. https:// doi.org/10.1016/j.stueduc.2013.09.009

Aubusson, P., Harrison, A., \& Ritchie, S. (Eds.). (2006). Metaphor and analogy in science education. Dordrecht: Springer. https:/ / doi.org/10.1007/1-4020-3830-5

Australian Broadcasting Corporation (2018). BTN. Retrieved from http:/ /www.abc.net.au/btn/

Ballard, H., Dixon, C., \& Harris, E. (2017). Youth-focused citizen science: Examining the role of environmental science and agency for conservation. Biological Conservation, 208, 65-75. https:/ / doi.org/10.1016/j.biocon.2016.05.024

Bandura, A. (1989). Human agency in social cognitive theory. American Psychologist, 44(9), 1175-1184.

Barron, B., \& Darling-Hammond, L. (2008). Teaching for meaningful learning: A review of research on inquirybased and cooperative learning. In L. Darling-Hammond, B. Barron, P. D. Pearson, A. H. Schoenfeld, E. K. Stage, T. D. Zimmermann, G. N. Cervetti, \& J. Tilson (Eds.), Powerful Learning. What we know about teaching for understanding (pp. 11-70). San Francisco: Jossey-Bass.

Bellino, M. E., \& Adams, J. D. (2017). A critical urban environmental pedagogy: Relevant urban environmental education for and by youth. The Journal of Environmental Education, 48(4), 270-284.

Bonney, R., Cooper, C. B., Dickinson, J., Kelling, S., Phillips, T., Rosenberg, K. V., \& Shirk, J. (2009). Citizen science: a developing tool for expanding science knowledge and scientific literacy. BioScience, 59(11), 977-984. https:// doi.org/10.1525/bio.2009.59.11.9

Buchanan, J. (2015). Metaphors as two-way mirrors: Illuminating pre-service to in-service teacher identity development. Australian Journal of Teacher Education, 40(10), 33-50. https:// doi.org/10.14221/ajte.2015v40n10.3

Buchanan, J., Schuck, S., \& Aubusson, P. (2016). In-school sustainability action: Climate Clever Energy Savers. Australian Journal of Environmental Education, 32(2), 154-173. https:/ / doi.org/10.1017/aee.2015.55 
Burn, K., \& Mutton, T. (2015). A review of 'research-informed clinical practice' in Initial Teacher Education. Oxford Review of Education, 41(2), 217-233. https:/ / doi.org/10.1080/03054985.2015.1020104

Cebrián, G., \& Junyent, M. (2015). Competencies in education for sustainable development: Exploring the student teachers' views. Sustainability, 7(3), 2768-2786. Retrieved from http://www.mdpi.com/2071$1050 / 7 / 3 / 2768 / \mathrm{htm}$

Cheng, Y., Lou, S., Kuo, S., \& Shih, R. (2013). Investigating elementary school students' technology acceptance by applying digital game-based learning to environmental education. Australasian Journal of Educational Technology, 29(1), 96-110. https:/ / doi.org/10.14742/ajet.65

Cooper, C. B. (2018). What is citizen science? Invited keynote address and public lecture, Australian Citizen Science Conference, Adelaide, S.A. 7-9 February.

Cooper, C. B. (2016). Citizen science: How ordinary people are changing the face of discovery. New York: Overlook Press. https:// doi.org/10.4136/ambi-agua.1996

Darling-Hammond, L. (2017). Teacher education around the world: What can we learn from international practice? European Journal of Teacher Education, 40(3), 291-309. https:/ / doi.org/10.1080/02619768.2017.1315399

Delaney, D., Sperling, C., Adams, C., \& Leung, B. (2008). Marine invasive species: Validation of citizen science and implications for national monitoring networks. Biological Invasions, 10(1), 1387-3547. https:/ / doi.org/10.1007/s10530-007-9114-0

Flagg, B. (2016). Contribution of multimedia to girls' experience of citizen science. Theory and Practice, 1(2), 1-13, https://doi.org/10.5334/cstp.51

Garbarino, J., \& Mason, C. E. (2016). The power of engaging citizen scientists for scientific progress. Journal of Microbiology \& Biology Education, 17(1), 7-12. https:/ / doi.org/10.1128/jmbe.v17i1.1052

Greenhow, C. \& Lewin, C. (2016). Social media and education: Reconceptualizing the boundaries of formal and informal learning. Learning, Media and Technology, 41(1), 6-30. https:/ / doi.org/10.1080/17439884.2015.1064954

Gündüz, Ş., Aşıksoy, G., \& Öksüz, U. (2018). Modular Curriculum Designed for the Environmental Education of $6^{\text {th }}$ and $7^{\text {th }}$ Grade Students in the North Cyprus. EURASIA Journal of Mathematics, Science and Technology Education, 14(6), 2133-2143. https://doi.org/10.29333/ejmste/85312

Huang, T., Chen, C., \& Chou, Y. (2016). Animating co-education: To see, feel, and discover in an augmented realitybased experiential learning environment. Computers and Education, 96, 72-82. https:// doi.org/10.1016/j.compedu.2016.02.008

Hummel, E. \& Randler, C. (2010). Experiments with living animals - effects on learning success, experimental competency and emotions. Procedia - Social and Behavioural Sciences, 2(2), 3823-3830. https:/ / doi.org/10.1016/j.sbspro.2010.03.597

Hiller, S., \& Katsantas, A. (2014). The effect of a horseshoe crab citizen science program on middle school student science performance and STEM career motivation. School Science and Mathematics, 114(6), 302-311. https:/ / doi.org/10.1111/ssm.12081

Hughes, R., \& Huby, M. (2004). The construction and interpretation of vignettes in social research. Social Work and Social Sciences Review, 11(1), 36-51. https:/ / doi.org/10.1921/17466105.11.1.36

Huseal, A., \& Abd-El-Khalick, F. (2014). Impact of a student-teacher-scientist partnership on students' and teachers' content knowledge, attitudes towards science, and pedagogical practices. Journal of Research in Science Teaching, 51(1), 84-115. https:/ / doi.org/10.1002/tea.21126

Inner West Council and City of Canterbury-Bankstown (2017). GreenWay Sustainability Project. Retrieved from https://www.greenway.org.au/arts-community/schools

Janis, S., Birney, L., \& Newton, R. (2016). Billion Oyster Project: Linking public school teaching and learning to the ecological restoration of New York Harbor using innovative applications of environmental and digital technologies. International Journal of Digital Content Technology and its Applications. Retrieved from http:/ / restoration.mspnet.org/index.cfm/31681

Kolb, D. (1984). Experiential learning: Experience as the source of learning and development. Englewood Cliffs, NJ: Prentice-Hall.

Krajcik, J. S., \& Czerniak, C. M. (2014). Teaching science in elementary and middle school: A project-based approach (4th Ed.). New York \& London: Routledge.

Krazny, M., \& Tidball, K. (2009). Community Gardens as Contexts for Science, Stewardship, and Civic Action Learning. Cities and the Environment, 2(1), 1-18. 
Kuh, G., \& Schneider, C. (2008). High-impact educational practices: What they are, who has access to them, and why they matter. Washington DC: Association of American Colleges and Universities.

Lai, H., Chang, C., Li, W., Fan, Y., \& Wu, Y. (2013). The implementation of mobile learning in outdoor education: Application of QR codes. British Journal of Educational Technology, 44(2). https://doi.org/10.1111/j.14678535.2012.01343.x

Le Féon, V., Henry, M., Guilbaud, L., Coiffait-Gombault, C., Dufrêne, E., Kolodziejczyk, E., ... Vaissière, B. (2016). An expert-assisted citizen science program involving agricultural high schools provides national patterns on bee species assemblages. Journal of Insect Conservation, 20(5), 905-918. https:/ / doi.org/https:/ / doi.org/10.1007/s10841-016-9927-1

Lewis, J., Oliver, R., \& Oliver, M. (2017). An evaluation of the impact of an agricultural science outreach program on the attitudes of rural students. Teaching Science: The Journal of the Australian Science Teachers Association, 63(2), 35-41.

Liu, Q., Gong, D., \& Chen, M. (2018). Applying Virtual Reality to Study the Effects of Environmental Education on College Students' Ethics and Environmental Literacy. EURASIA Journal of Mathematics, Science and Technology Education, 14(6), 2255-2263. https:// doi.org/10.29333/ ejmste/85937

Liu, F., Ritzhaupt, A.D., Dawson, K., \& Barron, K. (2017). Explaining technology integration in K-12 classrooms: a multilevel path analysis model. Education Technology Research and Development 65(4), 795-813. https:/ / doi.org/10.1007/s11423-016-9487-9

Lu, S., \& Liu, Y. (2013). Integrating augmented reality technology to enhance children's learning in marine education. Environmental Education Research, 21(4), 525-541. https:/ / doi.org/10.1080/13504622.2014.911247

McNight, K., O’Malley, K., Ruzik, R., Horsley, M., Franey, J., \& Bassett, K. (2016). Teaching in a digital age: How educators use technology to improve student learning. Journal of Research on Technology in Education, 48(3), 194-211. https:/ / doi.org/10.1080/15391523.2016.1175856

Maher, D., \& Yoo, J. (2017). Project based learning in the primary school classroom. Progress in Education, Volume 43. Hauppauge, NY: Nova Science Publishers.

Moursund, D. (1998). Project-based learning in an information technology environment. Learning and Leading with Technology, 25(8), 4.

Nordby, M., Knain, E., \& Jonsdottir, G. (2017). Vocational students' meaning-making in school science: authenticity through multimodal mobile learning. Nordic Studies in Science Education, 13(1), 52-65. https:/ / doi.org/10.5617/nordina.2976

Olmos-Raya, E., Ferreira-Cavalcanti, J., Contero, M., Concepción Castellanos, M., Giglioli, I., \& Alcañiz, M. (2018). Mobile virtual reality as an educational platform: A pilot study on the impact of immersion and positive emotion induction in the learning process. EURASIA Journal of Mathematics, Science and Technology Education, 14(6), 2045-2057. https:// doi.org/10.29333/ ejmste/ 85874

Pressick-Kilborn, K. (2015). Canalization and connectedness in the development of science interest. In K.A. Renninger, S. Hidi, \& M. Nieswandt (Eds.), Interest in Mathematics and Science Learning (pp. 353-367). Washington DC: American Educational Research Association (AERA).

Propen, D. (2015). Open Data, Environmental Conservation, and the Digital

Humanities: Mapping the Mangroves. Intellectual Property Caucus of the Conference on College Composition and Communication, pp. 30-33.

Renninger, K. A., \& Hidi, S. E. (2016). The power of interest for motivation and engagement. New York \& London: Routledge.

Rist, R., \& Hewer, S. (1996). What is learning technology? - Some definitions. In G. Stoner (Ed.), Implementing Learning Technology (pp. 3-5). Edinburgh, Institute for Computer Based Learning.

Rowe, K. (2014). In good hands? The importance of teacher quality. Educare News, 149, 4-14.

Schönfelder, M., \& Bogner, F. (2017). Two ways of acquiring environmental knowledge: By encountering living animals at a beehive and by observing bees via digital tools. International Journal of Science Education, 37(6), 723-741. https:/ / doi.org/10.1080/09500693.2017.1304670

Schuck, S., \& Aubusson, P. (2010). Educational scenarios for digital futures. Learning, Media and Technology, 35(3), 293-305.

Shah, H. R., \& Martinez, L. R. (2016). Current approaches in implementing citizen science in the classroom. Journal of microbiology \& biology education, 17(1), 17-22. https:/ / doi.org/10.1128/jmbe.v17i1.1032 
Shirk, J. L., Ballard, H. L., Wilderman, C. C., Phillips, T., Wiggins, A., Jordan, R., McCallie, E., Minarchek, M., Lewenstein, B. V., Krasny, M. E., \& Bonney, R. (2012). Public participation in scientific research: a framework for deliberate design. Ecology and Society, 17(2), 29. https:/ / doi.org/10.5751/ES-04705-170229

Smith, J., diSessa, A., \& Roschelle, J. (1993). Misconceptions reconceived: A constructivist analysis of knowledge in transition. The Journal of the Learning Sciences, 3(2), 115-163. https://doi.org/https:/ / doi.org/10.1207/s15327809j1s0302_1

Strauss, A., \& Corbin, J. (Eds.) (1997). Grounded theory in practice. Thousand Oaks: Sage Publications.

Tu, J., Chen, Y., \& Chen, S. (2017). The study of consumer green education via the Internet of Things with green marketing. EURASIA Journal of Mathematics, Science and Technology Education, 13(9), 6133-6145. https:/ / doi.org/10.12973/eurasia.2017.01054a

Turner, W. R., Oppenheimer, M., \& Wilcove, D. S. (2009). A force to fight global warming. Nature, 462(7271), 2789.

Van der Velde, T., Milton, A., Lawson, T., Wilcox, C., Landsell, M., Davis, G., ... Hardesty, B. (2017). Comparison of marine debris data collected by researchers and citizen scientists: Is citizen science data worth the effort? Biological Conservation, 208, 127-138. https:// doi.org/10.1016/j.biocon.2016.05.025

Vogel, B., Kurti, A., Milrad, M., Johansson, E., \& Müller, E. (2014). Mobile inquiry learning in Sweden: Development insights in interoperability, extensibility and sustainability of the LETS GO Software System. Educational Technology \& Society, 17(2), 43-57.

Wang, Y., Lavonen, J., \& Tirri, K. (2018). Aims for Learning 21st Century Competencies in National Primary Science Curricula in China and Finland. EURASIA Journal of Mathematics, Science and Technology Education, 14(6), 2081-2095. https:/ / doi.org/10.29333/ ejmste/86363

Weng, L., Hu, S., Tao, Z., \& Xu, J. (2018). The Rising of Green Society: Low-Carbon Consumption as a Result of Environmental Education in China. EURASIA Journal of Mathematics, Science and Technology Education, 14(6), 2169-2183. https:/ / doi.org/10.29333/ ejmste/85939

Wigley, T. (2018). The Paris warming targets: Emissions requirements and sea level consequences. Climatic Change, 147(1-2), 31-45.

Wilcox, C., Van Sebille, E., \& Hardesty, B. D. (2015). Threat of plastic pollution to seabirds is global, pervasive, and increasing. Proceedings of the National Academy of Sciences, 112(38), 11899-11904.

Yin, R. (2014). Case study research: Design and methods (5th ed.). Thousand Oaks: Sage Publications.

Zapf, M. (2010). Social Work and the Environment: Understanding People and Place. Critical Social Work, 11(3). Retrieved from http://www1.uwindsor.ca/criticalsocialwork/social-work-and-the-environmentunderstanding-people-and-place

Zeegers, Y., Paige, K., Lloyd, D., \& Roetman, P. (2012). ‘Operation Magpie': Inspiring teachers' professional learning through environmental science. Australian Journal of Environmental Education, 28(1), 27-41. https:/ / doi.org/10.1017/aee.2012.4

\section{http://www.ejmste.com}

